\title{
Ultratrace level speciation of Se, As and $S$ in atmospheric deposition at the high altitude Pic du Midi Observatory
}

\author{
ESTHER S BREUNINGER ${ }^{1,2}$, JULIE TOLU ${ }^{1,2}$, IRIS \\ THURNHERR $^{1}$, FRANZISKA AEMISEGGER ${ }^{1}$, SYLVAIN \\ BOUCHET $^{1,2}$, JEROEN E SONKE ${ }^{3}$, HEINI WERNLI ${ }^{1}$ AND \\ LENNY WINKEL ${ }^{1,2}$ \\ ${ }^{1}$ ETH Zurich \\ ${ }^{2}$ Eawag, Swiss Federal Institute of Aquatic Science and \\ Technology \\ ${ }^{3} \mathrm{CNRS} /$ Université de Toulouse \\ Presenting Author: esther.breuninger@usys.ethz.ch
}

The atmosphere is an important reservoir for the essential elements selenium (Se) and sulfur (S) as well as for the toxic element arsenic (As). Atmospheric wet and dry deposition are sources of these elements to ecosystems, agricultural soils and terrestrial food chains.

The fate of Se, S, and As, which is deposited to surface environments, notably their immobilization in soils versus bioavailability for plant uptake, strongly depends on the deposited chemical forms (speciation). The factors determining elemental speciation in atmospheric deposition are likely controlled by their speciation at the source (atmospheric emissions) as well as (bio)chemical transformations during transport. However, the drivers controlling Se and As speciation in atmospheric deposition remain poorly understood. Furthermore, previous studies have mostly focused on total elemental concentrations and/or a small number of species with large unidentified fractions. Generally, determining speciation of Se and As in atmospheric samples is challenging due to low concentrations, e.g., in the sub-ng $\mathrm{L}^{-1}$ range for precipitation and sub-pg $\mathrm{m}^{-3}$ for cloud water and aerosols. To tackle this issue, we developed a pre-concentration method and optimized different liquid chromatography methods coupled to ICP-MS/MS to determine $\mathrm{Se}$, As and $\mathrm{S}$ speciation in atmospheric samples.

We applied these methods on precipitation, cloud water and aerosol samples collected during Sept-Oct 2019 at Pic du Midi Observatory (French Pyrenees; 2877 m.a.s.1.). This site was selected as it allows for the investigation of local and long-range elemental transport from both marine and continental sources. To avoid species transformation after deposition and limit extent of source regions, high resolution sampling was carried out on a sub-event basis. This unique sampling strategy allowed us to link $\mathrm{Se}$, As, and S speciation to the main contributing moisture source areas and dominant atmospheric transport patterns, which were obtained by air parcel backward trajectories and Lagrangian moisture source analyses. Based on these analyses we will present here new insights into atmospheric sources and processes controlling Se and As speciation and total concentrations in precipitation. These insights are crucial to better understand and predict Se bioavailability and As toxicity in atmospheric deposition that functions as a source of these elements to surface environments. 